\title{
Grand Challenges in Coevolution
}

\author{
Mónica Medina ${ }^{1 *}$, David M. Baker ${ }^{2}$, David A. Baltrus ${ }^{3}$, Gordon M. Bennett ${ }^{4}$, \\ Ulisse Cardini ${ }^{5}$, Adrienne M. S. Correa ${ }^{6}$, Sandie M. Degnan ${ }^{7}$, Gregor Christa ${ }^{8}$, \\ Eunsoo Kim ${ }^{9}$, Jingchun $\mathrm{Li}^{10}$, David R. Nash ${ }^{11}$, Ezequiel Marzinelli ${ }^{12}$, Michele Nishiguchi ${ }^{13}$, \\ Carlos Prada ${ }^{14}$, Melissa S. Roth ${ }^{15}$, Mahasweta Saha ${ }^{16}$, Christopher I. Smith ${ }^{17}$, \\ Kevin R. Theis ${ }^{18}$ and Jesse Zaneveld ${ }^{19}$
}

${ }^{1}$ Department of Biology, Pennsylvania State University, University Park, State College, PA, United States, ${ }^{2}$ School of Biological Sciences and Swire Institute of Marine Science, The University of Hong Kong, Hong Kong, Hong Kong SAR, China, ${ }^{3}$ School of Plant Sciences, University of Arizona, Tucson, AZ, United States, ${ }^{4}$ Department of Life and Environmental Sciences, University of California, Merced, Merced, CA, United States, ${ }^{5}$ Integrative Marine Ecology Department, Stazione Zoologica Anton Dohrn - National Institute of Marine Biology, Ecology and Biotechnology, Naples, Italy, ${ }^{6}$ Department of Biosciences, Rice University, Houston, TX, United States, ' School of Biological Sciences, University of Queensland, Brisbane, QLD, Australia, ${ }^{8}$ Department of Zoology, Institute of Zoology, University of Wuppertal, Wuppertal, Germany, ${ }^{9}$ Division of Invertebrate Zoology and Sackler Institute for Comparative Genomics, American Museum of Natural History, New York, NY, United States, ${ }^{10}$ Department of Ecology and Evolutionary Biology, University of Colorado Boulder, Boulder, CO, United States, ${ }^{11}$ Department of Biology, University of Copenhagen, Copenhagen, Denmark, ${ }^{12}$ School of Life and Environmental Sciences, The University of Sydney, Sydney, NSW, Australia, ${ }^{13}$ Department of Molecular and Cell Biology, University of California, Merced, Merced, CA, United States, ${ }^{14}$ Department of Biological Sciences, University of Rhode Island, Kingstown, RI, United States, ${ }^{15}$ Department of Plant and Microbial Biology, University of California, Berkeley, Berkeley, CA, United States, ${ }^{16}$ Marine Ecology and Biodiversity, Plymouth Marine Laboratory, Plymouth, United Kingdom, ${ }^{17}$ Department of Biology, Willamette University, Salem, OR, United States, ${ }^{18}$ Department of Biochemistry, Microbiology and Immunology, Wayne State University School of Medicine, Detroit, MI, United States, ${ }^{19}$ Division of Biological Sciences, School of Science Technology Engineering and Math, University of Washington Bothell, Bothell, WA, United States

\section{OPEN ACCESS}

Edited and reviewed by: Mark A. Elgar,

The University of Melbourne, Australia

${ }^{*}$ Correspondence: Mónica Medina momedinamunoz@gmail.com

Specialty section:

This article was submitted to Coevolution,

a section of the journa

Frontiers in Ecology and Evolution

Received: 16 October 2020 Accepted: 23 November 2021

Published: 06 January 2022

Citation:

Medina M, Baker DM, Baltrus DA Bennett GM, Cardini U, Correa AMS, Degnan SM, Christa G, Kim E, Li J, Nash DR, Marzinelli E, Nishiguchi M,

Prada C, Roth MS, Saha M, Smith Cl,

Theis KR and Zaneveld J (2022)

Grand Challenges in Coevolution.

Front. Ecol. Evol. 9:618251. doi: 10.3389/fevo.2021.618251
Keywords: microbiome, symbiosis, network, holobiont, coevolution

\section{COEVOLUTION}

Coevolution-reciprocal evolutionary change between interacting lineages (Thompson, 1994; see Glossary) - is thought to have played a profound role in the evolution of Life on Earth. From similar patterns across the wings of unrelated lineages of butterflies (Hoyal Cuthill and Charleston, 2015), egg mimicry of "cheating" brood parasites (Davies, 2010), to the role of animal pollinators in driving the diversification of flowering plants (Kay and Sargent, 2009), to the ubiquity of sexual reproduction and sexual conflicts (Hamilton, 2002; Arnqvist and Rowe, 2005; King et al., 2009), the formation of the eukaryotic cell (Martin et al., 2015; Imachi et al., 2020), and even the origin of living organisms themselves (Mizuuchi and Ichihashi, 2018), evolutionary changes among interacting lineages have played profound and important roles in the history of Life.

This Grand Challenges inaugural contribution encompasses eclectic opinions of the editorial board as to what are the next frontiers of coevolution research in the 21st century. Coevolutionary biology is a field that has garnered a lot of attention in recent years, in part as a result of technical advances in nucleotide sequencing and bioinformatics in the burgeoning field of host-microbial interactions. Many seminal studies of coevolution examined reciprocal evolutionary change between two or a few interacting macroscopic species that imposed selective pressures on one another (e.g., insect or bird pollinators and their flowering host plants). Understanding the contexts under which coevolution occurs, as opposed to scenarios in which each partner adapts independently to a particular environment (Darwin, 1862; Stiles, 1978) is important to elucidate coevolutionary processes. A whole spectrum of organismal interactions has been examined under the lens of coevolution, providing additional context, and nuance to ecological strategies traditionally categorized as ranging from beneficial to detrimental for participating 
species (Figure 1). In particular, a coevolutionary perspective has revealed that even "mutualisms" are not always fully beneficial or cooperative for the partners involved. Instead, the tendency to "cheat" permeates across symbiotic partnerships (PerezLamarque et al., 2020). Conversely, recent evidence suggests that non-lethal predation by co-evolved predators, which has traditionally been assumed to be entirely antagonistic, may provide sessile prey with some indirect benefit through enhanced opportunities to acquire beneficial symbiotic microorganisms (Grupstra et al., 2021). Herein, we discuss some of the recent areas of active research in coevolution, restricting our focus to coevolution between interacting species.

\section{COEVOLUTION AND DIVERSIFICATION}

Among multicellular eukaryotes, an enduring question is whether interactions between organisms have played a role in promoting speciation and diversification over evolutionary time (Thompson, 1989; Althoff et al., 2014; Hembry et al., 2014; Maron et al., 2019). Naturalists have argued since the 19th century that interactions with pollinators may have spurred the dramatic and rapid diversification of flowering plants (Grant, 1949; Friedman, 2009). Similarly, Ehrlich and Raven, who first coined the term "coevolution," argued that the origin of novel defensive chemicals in members of the Apiaceae (plants in the carrot family) may have served as "key innovations" that allowed them to avoid plant-feeding insects and colonize new habitats. Herbivorous insects that evolved compensatory mechanisms to tolerate or neutralize these toxins could then have recolonized these plants and, freed from competition with other insects, themselves diversified (Ehrlich and Raven, 1964). Patterns at a macroevolutionary scale offer multiple lines of evidence to support these conjectures. The diversification of flowering plants in the Jurassic and Cretaceous eras coincided with the diversification of pollinators (Grimaldi, 1999), followed by the evolution of herbivorous insects that specialized on flowering plants (Farrell, 1998). Further corroborating coevolution as a driver of diversification, these insects that feed on flowering plants are vastly more diverse than those that are generalist pollinators (Mitter et al., 1988; Farrell, 1998), even when controlling for time. Additionally, plants that rely on specialized pollinators are more diverse than those with generalized pollinators (Dodd et al., 1999; Sargent, 2004; Kay and Sargent, 2009). Finally, species that have particularly strong or highly specialized ecological interactions, such as hosts and parasites or plants and insects involved in obligate pollination mutualisms, often show patterns of "phylogenetic congruence"-for example any particular species of parasite is often most closely related to parasites that feed on their host's nearest relatives (Page, 1996; Paterson et al., 2000; Weiblen, 2004).

Connecting these broadscale patterns to evolutionary and ecological mechanisms, and specifically evaluating the role of coevolution at the microevolutionary scale in generating diversity at a macroevolutionary level remains a major challenge (Hembry et al., 2014). Theoretical treatments have made different predictions about the circumstances under which reciprocal natural selection may promote evolutionary divergence and reproductive isolation (Kiester et al., 1984; Yoder and Nuismer, 2010), and empirical studies have produced contradictory results. Whereas early work suggested that mutualistic interactions such as those between plants and their pollinators could prompt speciation, more recent modeling work suggests that mutualisms are more likely to promote evolutionary stasis (Yoder and Nuismer, 2010). Predominantly antagonistic interactions on the other hand can promote evolutionary divergence at a populationlevel, depending on the factors that mediate the fitness of each player. In cases of escalating coevolution-in which antagonists evolve ever stronger defenses and counter defenses-rapid divergence in phenotypes between populations may arise (Brodie et al., 2002; Brodie and Ridenhour, 2003). For example, among brood parasites like cuckoos that lay their eggs in the nests of other birds, the cuckoos experience natural selection that more and more closely matches the coloration and patterning of their eggs to those of their local hosts (Spottiswoode and Stevens, 2012). The birds whose nests are parasitized by cuckoos in turn rapidly evolve more complex patterning in their own eggs (Yang et al., 2010; Spottiswoode and Stevens, 2012). Host birds may also experience enhanced capacity to recognize and expel the eggs of their cuckoo parasites (Soler et al., 2001). Populations that occur in regions where the cuckoo is absent fail to eject even grossly mismatched eggs (Soler and Møller, 1990). There is contradictory evidence, however, as to whether arms-race coevolution of this type results in greater rates of diversification (Smith and Benkman, 2007; Krüger et al., 2009; Fossøy et al., 2016).

To generate empirical evidence that coevolution per se is the causal mechanism of diversification, another challenge, and perhaps a more fundamental one, is ruling out alternative explanations of diversification (Althoff et al., 2014). Patterns suggestive of reciprocal adaptation can arise through adaptation by one of the two interacting species alone (that is, natural selection without reciprocal adaptation), or even through neutral processes that do not involve selection at all (Janzen, 1980; Yoder and Nuismer, 2010). Patterns of phylogenetic congruence, for example, may be the product of a common biogeographic history rather than "cospeciation" (Smith et al., 2008; Althoff et al., 2012, 2014) and the greater diversity of organisms that are involved in specialized interactions might not indicate that the interactions themselves prompted higher rates of speciation (Armbruster and Muchhala, 2009). "Phenotype matching"correlations in the features of interacting species such as floral structures that match features of their pollinators (Nilsson, 1988) or defenses against predators that are met by equally strong counter defenses (Brodie and Ridenhour, 2003) —although often taken as evidence for coevolution can arise due to extrinsic forces, or even through simple genetic drift (Nuismer et al., 2010). Finally, selection by climate, edaphic soil factors, and other extrinsic forces may be more important than coevolution 


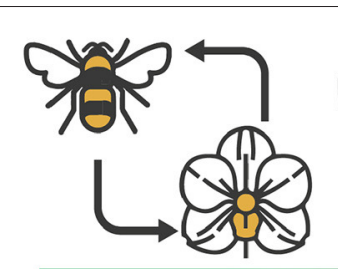

MUTUALISTIC

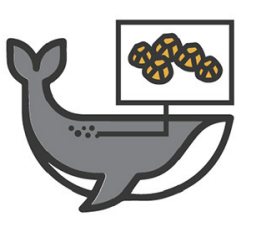

COMMENSAL

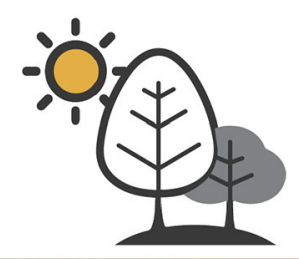

COMPETITIVE

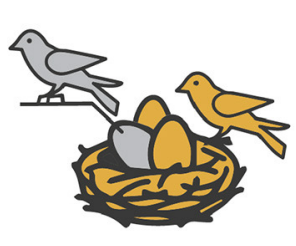

ANTAGONISTIC

$+/+$

$+/ 0$ $+/-$

FIGURE 1 | Spectrum of species interactions range from mutualistic to antagonistic. Mutualistic: plants and their pollinators, such as orchids and orchid bees. Both members benefit from the interaction. Commensal: Barnacles benefit from settling on the whale's skin surface, but do not impact the whale. Competitive: plants competing for access to canopy light in a forest. Antagonistic: The cuckoo lays its egg in the nest of another species of (host) bird. The host bird incurs the cost of raising the cuckoo's young instead of its own (which the cuckoo hatchling destroys).

per se in driving divergence between populations (Nuismer and Gandon, 2008).

This difficulty in reconciling compelling macroevolutionary patterns that suggest coevolution drives speciation in eukaryotes with the paucity of evidence at the ecological and microevolutionary scale thus constitutes a "grand challenge" in coevolution.

\section{THE COMPLEXITY OF THE HOLOBIONT COMPLICATES COEVOLUTIONARY ANALYSIS}

An additional, newer "grand challenge" stems from the emerging realization that every macroorganism is actually a holobiont-a host organism together with all of the resident microorganisms living on or in it symbiotically. Thus, virtually every coevolutionary interaction has the potential to represent a diffuse or guild coevolution, in which a single species coevolves with a guild and/or two guilds coevolve (e.g., Janzen, 1980), rather than a two-partner interaction. Studying diffuse interactions is inherently more challenging than two-partner interactions because of the higher number of entities (and their potential interactions) involved. Further, when many partners are involved (e.g., in a holobiont), each partner will have its own generation time, mutation rate and specific biology, adding additional complexity. Yet research effort directed toward diffuse interactions (e.g., Matthews et al., 2020) has become common practice due to increased research in hostmicrobiome interactions across many taxa. Given that research challenges increase exponentially in more complex coevolving assemblages, it is important to discriminate between interactions that represent outcomes of coevolution vs. those that are outcomes simply of evolution. Building such a framework will require integrating the jargon (e.g., microbiome) and concepts-such as the holobiont (Margulis and Fester, 1991; Bordenstein and Theis, 2015) and the hologenome (Collens et al., 2019)_of microbial ecology with those of the broader coevolutionary literature. It will further require the development of reliable tests for coevolution at multiple scales of biological organization (e.g., coevolution at the gene, genome, metabolic and organismal levels). Holobionts can, therefore, be thought of as interacting community members that are best visualized as complex networks of diffuse interactions (Bascompte, 2019). All partners may be genuinely coevolving, or each may be independently adapting to (shared) selective pressures in their own (shared) environments. Alternatively, a holobiont may be a mixture of both (Bordenstein and Theis, 2015). A role of coevolutionary research is to help position core members vs. transient members along a coevolutionary spectrum. The selective forces shaping coevolving organisms are different from those in independently evolving but codiversifying taxa. Coevolutionary networks are dynamic, and depending on the types of interactions nested within them, and the extent of external perturbations (e.g., climate change), they can lead to different diversification outcomes (Thompson, 2006) (Figure 2).

It is well-established that microbes affect the physiology and development of most if not all eukaryotic organisms (Gilbert and Epel, 2015; Gilbert et al., 2015; Peixoto et al., 2021). Although it is tantalizing to imagine if and how these microbes have coevolved with both unicellular and multicellular eukaryotic hosts, and to make assumptions about evolutionary processes underlying noticeable patterns in community structures, we still lack a basic framework for testing whether host-microbiome coevolution has occurred. One area that is worth exploring involves the ongoing endosymbiosis among eukaryotic or prokaryotic partners, where complimentary genomic and metabolic functional reductions can be assessed. For example, some diatoms have incorporated cyanobacteria that perform nitrogen fixation, and the cyanobacterium has since lost its photosynthetic ability (Nakayama et al., 2014). Similar processes have been repeatedly observed in lichens (Pogoda et al., 2018). Even in experimental evolution systems involving pairs of microbes, rigorous tests of coevolution (e.g., using time-shift pairings of ancestral vs. evolved partners) are major undertakings with many technical challenges (e.g., Hillesland and Stahl, 2010). We propose a general consensus for coevolutionary theory that requires phenotypic changes in coevolving organisms (or guilds) to influence fitness in a reciprocal matter. The 


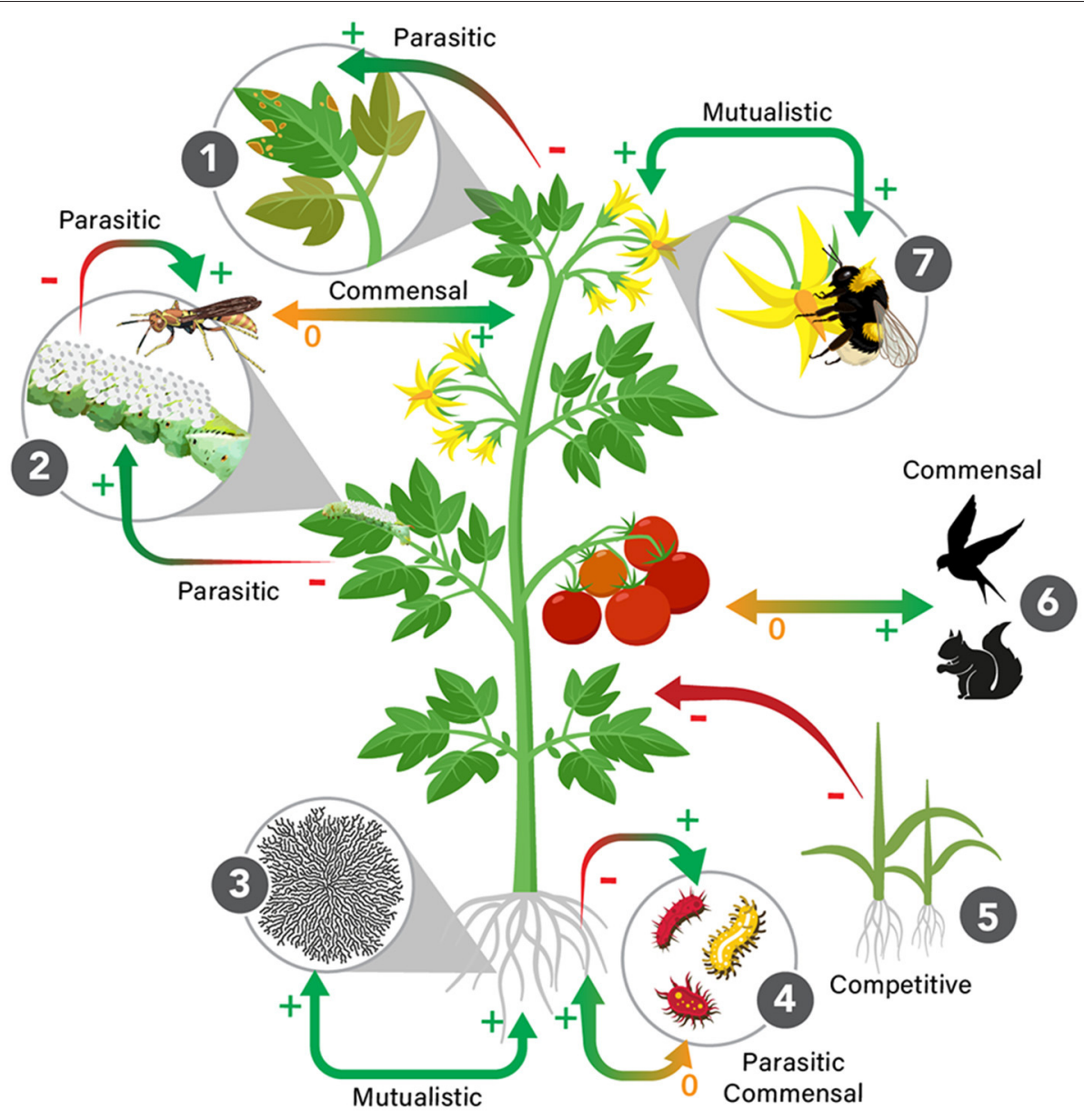

FIGURE 2 | Coevolutionary networks, such as the vertebrates, invertebrates, plants and microorganisms that interact with tomato plants (Solanum spp.), result in species interactions with different levels of codependency. 1: common rust fungus can infect the tomato plant, leading to leaf mortality; 2: a wasp caterpillar parasite; 3: Arbuscular mycorrhyzal fungi (AMF) are plant symbionts; 4: invertebrates and microorganisms such as nematodes and bacteria can have detrimental effects on plant roots; 5: other plant species can compete with Solanum for nutrients and space crop fields; 6: frugivores benefit from consuming tomato fruits and disperse seeds; and 7: pollinators such as bees contribute to the plants reproductive output. $0=$ neutral interaction, $+=$ beneficial, $-=$ detrimental.

field will need to demand specific and sufficient evidence to demonstrate that host-microbiome coevolution is indeed happening. The nature of evidence sufficient to demonstrate such coevolution also still needs to be determined. The development of a standardized set of tools to evaluate the potential for coevolution across hosts, as well as the creation and elaboration of neutral models for microbiome community assembly and evolution in the absence of coevolution, will support the development of a framework for testing for host-microbiome coevolution. Detailing the nature of what constitutes sufficient evidence, and of a standardized tool set, is outside the scope of this opinion piece. Unraveling eco-evolutionary processes (Blasco-Costa et al., 2021) proposes the use of interaction trait codependency as well as geographical network modularity to shed light on the mechanisms driving, or not, coevolutionary processes. We encourage the coevolution community to build new analytical tools that combine community assembly theory with cophylogenetic theory (e.g., Russo et al., 2018).

\section{DIFFERENT SPATIO-TEMPORAL SCALES OFFER A VARIETY OF PERSPECTIVES ON COEVOLUTION}

The definition of symbiosis across research fields ranging from microbiology to ecology sometimes differs, reflecting the emphases on different types of interactions. Herein, we use the original definition of symbiosis (De Bary, 1879; Oulhen et al., 2016), thus one should not assume a priori that all (or indeed any) symbiotic (i.e., coresident) partners in a holobiont are coevolving. In intimate interactions that require metabolic complementarity, understanding the dynamics of species coupling (e.g., horizontally vs. vertically transmitted symbionts) over ontogeny is paramount to be able to develop coevolutionary models that incorporate the molecular underpinnings of fitness in all partners (Roughgarden et al., 2018; Lloyd and Wade, 2019; Correa et al., 2021). Ecological theory has developed concepts such as facilitation to describe predominantly positive species 
interactions (Bruno et al., 2003). Symbiotic organisms are often coevolving and can also be understood in a framework of the evolution of cooperation (Herre et al., 1999; Kiers and Van Der Heijden, 2006). Other well-established ecological theories may be applicable where negative coevolutionary interactions are involved (e.g., host-parasite). The main idea is that coevolving groups may represent a single unit of selection. A healthy debate has been taking place in the literature, that moves beyond absolutist views of pure independence (e.g., no cooperation) or pure interdependence (e.g., the full holobiont as the unit of selection) in fitness, and instead increasingly asks to what degree, and in which direction (e.g., predominantly mutualism vs. commensalism vs. parasitism) and under what conditions holobiont members coevolve (Herre et al., 1999; Bordenstein and Theis, 2015; Moran and Sloan, 2015; Lloyd and Wade, 2019). If a lineage of microbes has codiversified with its host over evolution, coevolutionary research should aim to determine whether those microbes are more likely to be "keystone species" serving a set of "core" functions or whether there is convergence in the set of microbial functions rather than organismal coevolution (Doolittle and Inkpen, 2018).

Stressors often alter the temporal or interindividual variability in the microbiome. The literature on how and why microbiomes vary with stress offers contrasting predictions for how these changes influence host health and fitness. On the one hand, if microbiomes are tightly regulated by their host (even during physiological stress), variability in the microbiome in the face of stress might represent "fine-tuning" of the microbiome to better cope with that stress (e.g., the coral probiotic hypothesis) (Reshef et al., 2006). Conversely, physiological stress could produce microbiome variance by reducing the ability of the host to regulate its microbiome, a process coined as the Anna Karenina Principle (AKP) (Zaneveld et al., 2017). Under the AKP, microbiome variance during physiological stress may represent a loss of host control that could be neutral or harmful for host health. Another possibility is that microbial contributions to holobiont function could vary based on the holistic composition of microbes present, due to facilitative or competitive interactions (e.g., McIlroy et al., 2019) arising due to complementarity effects (Tilman et al., 1997; Loreau, 1998; Fox, 2005). Empirically testing these contrasting predictions with diverse hosts, microbial groups (e.g., Claar et al., 2020; Howe-Kerr et al., 2020) and stressors may paint a more complete picture of what happens when stress perturbs holobiont dynamics, yet specific attention needs to be given to whether stress-driven outcomes are the result of coevolving taxa.

A key concept investigated in evolution is adaptive phenotypic plasticity and how it can generate fixed traits through genetic assimilation of alternative phenotypes (Schlichting and Pigliucci, 1998; West-Eberhard, 2003; Pigluicci and Muller, 2010). The subset of symbionts that organisms have at the present time may come from a much larger pool that was available to their ancestors and then later became fixed (Waddington, 1953; West-Eberhard, 2003; Lande, 2009). The ability to establish relationships with symbiotic partners could therefore be plastic, depending on lineage-specific environmental and historical factors; this can be tested by applying phylogenetic tools and sampling enough partners. Phylogenetic inference will also assist in understanding whether symbiotic interactions that often result in coevolutionary patterns can arise equally often from mutualistic, commensalistic, and parasitic relationships (Thompson and Fernandez, 2006). It is still uncertain under what conditions coevolving taxa act as mutualists and under what conditions they become parasitic (e.g., Baker et al., 2018) or pathogenic (Lesser et al., 2013; Correa et al., 2021). Variability in outcomes is one of the pillars of the geographic mosaic theory of coevolution, and is therefore likely to be one of the drivers of coevolution (and certainly of maintaining the genetic variability required for coevolution) (Thompson, 1994). The driving pressures governing each type of interaction, and the plasticity to move between those types of interactions, remain unknown. Nonetheless, phenotypic plasticity provides a mechanism to understand "fixed" relationships. The evolution of eusociality provides a good example. Once eusociality evolves, social and solitary behaviors can be fixed in species or populations back and forth by expressing preexisting alternative phenotypes via developmental switches that are turned on and off depending on the ecological/environmental context (Field et al., 2010). Developmental plasticity thus provides a robust framework to understand the labile phylogenetic pattern of fixation of solitary and social behaviors and the traits that facilitate them (Wittwer et al., 2017) across species in many insect groups.

With respect to microbiomes, there is a considerable challenge in isolating individual species to ascertain their function (McIlroy et al., 2020). Metabolic versatility is accomplished in holobionts thanks to the simultaneous occurrence of disparate biochemical machineries of symbionts, whose roles within the host can convergently evolve (e.g., McCutcheon et al., 2009). However, we still lack an understanding of the biogeochemical and ecological functions, as well as the establishment and maintenance, of many of these relationships (Beinart, 2019). This is despite these functional relationships likely contributing in an important way to the flows of energy and matter within their ecosystem (e.g., Thurber et al., 2017; Cardini et al., 2019; Zimmerman et al., 2020), and across spatial and organizational scales (Pita et al., 2018). It becomes important to investigate to what extent coevolution within and among holobionts is an agent of ecosystem change.

\section{MOLECULAR COEVOLUTION}

Organisms that engage in coevolutionary interactions impose reciprocal selection that should leave molecular signatures (e.g., horizontal gene transfer, natural selection) across their genomes. Until recently, it remained challenging to explicitly test questions of the genetic mechanisms that underlie coadapted organismal complexes, due to difficulties in identifying all interacting organisms and assaying entire genomes for signatures of selection. Advances in multi-omics technologies provide the capabilities to test specific hypotheses of how interacting organisms shape each other's genomes (e.g., Degnan, 2014). For example, in obligate animal-bacterial symbioses, full-genome sequencing has revealed that the genomes of bacterial symbionts are shaped by the host environment, often leading to metabolic 
specialization and extreme genome size reduction (reviewed in McCutcheon and Moran, 2012). In order to manage and sustain these relationships, animal hosts are known to evolve specialized organs that deliver tailored support by reprogramming the expression of thousands of eukaryotic genes (Hansen and Moran, 2011; Belcaid et al., 2019). Some of these support genes evolved from the duplication of existing host genes, the repurposing of genes that supported more ancient symbioses (e.g., mitochondria), or the horizontal transfer of bacterial genes to the host nuclear genomes (Husnik et al., 2013; Sloan et al., 2014; Mao et al., 2018). When different organisms live in close contact with each other, this can lead to molecular interactions (e.g., protein-protein, protein-nucleic acids) of different origins. Coevolutionary research should investigate the consequences of such interactions and whether they offer an opportunity for metabolic innovation (and not simply the transfer of a metabolic module) that may otherwise be difficult to attain by mutations or lateral transfer of individual genes. Investigation into the metabolic aspects of eukaryogenesis, which involved interactions of two or more microbial species, as well as the evolution of eukaryotic photosynthesis, may provide a historical context for the re-wiring of interactome and regulatory networks in symbioses (e.g., Burns et al., 2018; Leitão et al., 2020).

\section{RECOGNIZING HOMOLOGY AND HOMOPLASY IN THE EVOLUTION OF SYMBIOSIS}

In cases where coevolution is repeatable, one untested prediction is that phenotypic traits will emerge when two or more organisms interact in an intricate matter. A classic example is the case of photosymbiosis. Multiple photosynthetic microbial taxa (e.g., cyanobacteria, green algae, dinoflagellate algae) have established mainly endosymbiotic symbiosis with diverse heterotrophic eukaryotic hosts including fungi (e.g., lichens), unicellular protists (e.g. Chlorella-bearing ciliates, foraminifera, mixotrophic testate amoebae) (Hallock, 1999; Proeschold et al., 2011; Gomaa et al., 2014), and animals (e.g., reef-building corals, viridissima group of Hydra) (Stanley, 2006; Kawaida et al., 2013; van Oppen and Medina, 2020). Understanding whether the same molecular machinery is involved in establishing and maintaining photosymbiosis each time, poses interesting questions about when we should consider a trait as homologous vs. convergent (Stoecker et al., 2009; Melo Clavijo et al., 2018; Li et al., 2020). Studying similar types of symbioses across diverse organisms will lend itself not only to mechanistic discoveries, but also to advancing conceptual debates. In morphological evolution, shared traits that are homologs often show important mechanistic similarities that are not shared in convergently evolved traits (Scotland, 2010). During holobiont evolution, animal-microbe or plant-microbe symbioses may persist through evolution or may evolve convergently. A major goal in coevolutionary research will be to distinguish homologous symbioses from homoplasies to elucidate if the same patterns extend to different underlying molecular mechanisms. Although the molecular mechanisms regarding many symbioses still await elucidation, preliminary data show that convergently evolved symbiotic associations sometimes display the same molecular level adaptations. For example, both corals (Cnidaria) and giant clams (Mollusca) are known to host algae from the family Symbiodiniaceae (Trench, 1979), although the symbiosis is intracellular for corals (Davy et al., 2012) and extracellular for the bivalves (Ip and Chew, 2021). However, these two distantly related animal lineages both utilize the vacuolar $\mathrm{H}^{+}$-ATPase gene (VHA) to acidify their symbiont-containing environments, thereby facilitating the carbon concentrating process, and promoting algal photosynthesis (Barott et al., 2015; Armstrong et al., 2018). Vacuolar $\mathrm{H}^{+}$-ATPase is a highly conserved gene in eukaryotes (Anraku et al., 1992), and neither host lineage possesses "special" versions of VHA compared to their non-symbiotic relatives ( $\mathrm{Li}$ et al., 2020). Therefore, adaptations to photosymbiosis appear to have occurred at the regulatory/expression level, specifically by expressing VHA in the symbiont-containing cells/tissues (Barott et al., 2015; Armstrong et al., 2018). This example indicates that molecular-level parallel evolution can occur in convergently evolved symbiosis. Future research efforts are needed to examine this phenomenon, and special attention needs to be paid to gene regulatory mechanisms.

\section{MICROBIOMES CAN INFLUENCE THE EVOLUTION OF HOST BEHAVIORAL TRAITS}

Mounting evidence suggests that animal behavioral phenotypes can be influenced by the microbiome (Archie and Theis, 2011; Ezenwa et al., 2012; Zhu et al., 2018; Vernier et al., 2020). Specifically, the microbiome can contribute to host anti-predator behaviors, increase host foraging efficiency and reproductive output, and mediate host communication (Theis et al., 2020). In some instances, for example in the bioluminescence-enabled camouflaged antipredator behavior of bobtail squids, a single microbial symbiont, Vibrio fischeri, contributes directly to a host behavioral phenotype that is under strong selective pressure. In other cases, such as mammals scent marking with secretions from specialized integumental scent glands, a diverse suite of microbial symbionts appears to contribute behaviorally-relevant components to the chemical signaling phenotypes of their hosts. Hypotheses such as this are ample fodder for elucidating the intricacies of the proximate and ultimate relationships between hosts and their various symbionts in specific organs and among the symbionts themselves in generating the complex phenotypes of holobionts (Carthey et al., 2018). For instance, if the holobiotic hypothesis for animal chemical communication is correct, then: (1) scent organs should harbor odor-producing microbes that exhibit phylosymbiosis across host clades; (2) both the microbial and odor profiles of these organs should vary with the host traits being signaled, and these profiles should covary; (3) experimental manipulation of scent organ microbiomes should alter organ odor profiles; and (4) doing so should result in altered receiver responses to those manipulated signals. These sorts of investigations are facilitated by current advances in omics technologies, which enable us to determine whether a 
specific microbial signature associates with a specific behavioral pattern within animal populations and across animal evolution or whether there are holobiont configurations that are favored if there is selective pressure for a certain behavioral trait (Theis et al., 2020).

\section{CLIMATE CHANGE}

How organisms cope, acclimatize, and adapt in dynamic and changing environments, particularly within the context of global change, is critical to the future of our planet and its organisms. We must understand how host organisms live in association with microbial symbionts and how they will respond individually, together, or through changing associations, adding dimensions of complexity to the identification and study of coevolutionary relationships. Moreover, the biological diversity of phenotypes, genotypes, and organisms, which underlie the potential for differences and possibilities, has not been fully characterized (Pereira et al., 2012). There is a need to assess how the mismatch in the rates at which microorganisms evolve vs. the rates at which macroorganismal hosts evolve and respond to environmental changes, as this influences the condition and performance of holobionts (e.g., Kiers et al., 2010; Correa and Baker, 2011; van Oppen et al., 2011). Short-term experiments examining the effects of environmental changes on habitat-forming hosts (e.g., plants, corals, seaweeds) show a link between changes in hostassociated microbes in response to environmental stressors (Buerger et al., 2020; Morella et al., 2020; Saha et al., 2020), which then translate into effects on the host. Changes in environmental parameters will be gradual (with the exception of extreme events like heat waves, floods and other anomalies) and may interact in complex ways (Qiu et al., 2019). This timeline may allow for microorganisms to evolve, leading to communities that could be resistant to those changes, potentially influencing holobiont resilience to climate change. Understanding the coevolutionary responses of host and their associated microbes to stressors is critical in order to better predict the effects of environmental changes on holobionts. In turn, this understanding will most effectively leverage microbial ecology to inform conservation efforts.

In the Anthropocene, new diseases and environmental extremes are on the rise (Egan and Gardiner, 2016). A grand

\section{REFERENCES}

Althoff, D. M., Segraves, K. A., and Johnson, M. T. J. (2014). Testing for coevolutionary diversification: linking pattern with process. Trends Ecol. Evol. 29, 82-89. doi: 10.1016/j.tree.2013.11.003

Althoff, D. M., Segraves, K. A., Smith, C. I., Leebens-Mack, J., and Pellmyr, O. (2012). Geographic isolation trumps coevolution as a driver of yucca and yucca moth diversification. Mol. Phylogenet. Evol. 62, 898-906. doi: 10.1016/j.ympev.2011.11.024

Anraku, Y., Umemoto, N., Hirata, R., and Ohya, Y. (1992). Genetic and cell biological aspects of the yeast vacuolar $\mathrm{H}^{+}$-ATPase. J. Bioenerg. Biomembr. 24, 395-405. doi: 10.1007/BF00762532

Archie, E. A., and Theis, K. R. (2011). Animal behaviour meets microbial ecology. Anim. Behav. 82, 425-436. doi: 10.1016/j.anbehav.2011.05.029 challenge will be to develop synthetic holobionts with enhanced resistance or resilience to stressors (Damjanovic et al., 2017; Wood et al., 2019). Synthetic holobionts can be of substantial benefit to areas of environmental remediation, restoration, conservation, or crop improvement (e.g., Coleman and Goold, 2019). However, our exploration of the ethical issues and ecological implications of synthetic holobionts in the study and trajectories of coevolutionary relationships are in their infancy (e.g., Filbee-Dexter and Smajdor, 2019). For example, symbiotic networks of microorganisms can affect the naturalization of invasive species in the introduced region and the ability of these organisms to outcompete native counterparts. Invasion mechanisms employed by some plants involve microbiome shifts between the native and invaded habitats, leading to enhanced resource acquisition and affecting the ability of these plants to outcompete native species (Coats and Rumpho, 2014). In ants, symbiont communities can help their hosts by buffering behavioral changes caused by interspecies competition as a consequence of biological invasions (Cheng et al., 2019). These examples substantiate the need to understand the mechanisms underlying the success of invasive holobionts, highlighting the potential implications for conservation biology. Coevolutionary research should enable us to apply what we know to create cleaner solutions to reduce the human footprint on Earth and sustain diversity on our planet.

\section{AUTHOR CONTRIBUTIONS}

MM outlined the manuscript and drafted the figures. All other authors contributed equally to the development of ideas and writing of the document.

\section{FUNDING}

MM was funded by NSF OCE 1442206. EK was supported by NSF CAREER 1453639. CP has been supported with NSFOIA 2032919 and USDA-NIFA 1017848. Plymouth Marine Laboratory is acknowledged for awarding a PML Fellowship to MS.

\section{ACKNOWLEDGMENTS}

We thank Justin Wheeler for making the final figures.

Armbruster, W. S., and Muchhala, N. (2009). Associations between floral specialization and species diversity: cause, effect, or correlation? Evol. Ecol. 23, 159-179. doi: 10.1007/s10682-008-9259-z

Armstrong, E. J., Roa, J. N., Stillman, J. H., and Tresguerres, M. (2018). Symbiont photosynthesis in giant clams is promoted by V-type $\mathrm{H}^{+}$-ATPase from host cells. J. Exp. Biol. 221, 177220. doi: 10.1242/jeb. 177220

Arnqvist, G., and Rowe, L. (2005). Sexual Conflict. Princeton, NJ: Princeton University Press. doi: 10.1515/9781400850600

Baker, D. M., Freeman, C. J., Wong, J. C. Y., Fogel, M. L., and Knowlton, N. (2018). Climate change promotes parasitism in a coral symbiosis. ISME J. 12, 921-930. doi: 10.1038/s41396-018-0046-8

Barott, K. L., Venn, A. A., Perez, S. O., Tambutteeé, S., and Tresguerres, M. (2015). Coral host cells acidify symbiotic algal microenvironment 
to promote photosynthesis. Proc. Natl. Acad. Sci. U.S.A. 112, 607-612. doi: $10.1073 /$ pnas. 1413483112

Bascompte, J. (2019). Mutualism and biodiversity. Curr. Biol. 29, R467-R470. doi: 10.1016/j.cub.2019.03.062

Beinart, R. A. (2019). The significance of microbial symbionts in ecosystem processes. mSystems. 4, e00127-19. doi: 10.1128/mSystems.00127-19

Belcaid, M., Casaburi, G., McAnulty, S. J., Schmidbaur, H., Suria, A. M., MorianoGutierrez, S., et al. (2019). Symbiotic organs shaped by distinct modes of genome evolution in cephalopods. Proc. Natl. Acad. Sci. U.S.A. 116, 3030-3035. doi: $10.1073 /$ pnas. 1817322116

Blasco-Costa, I., Hayward, A., Poulin, R., and Balbuena, J. A. (2021). Nextgeneration cophylogeny: unravelling eco-evolutionary processes. Trends Ecol. Evol. 36, P907-P918. doi: 10.1016/j.tree.2021.06.006

Bordenstein, S.R., and Theis, K.R. (2015). Host biology in light of the microbiome: ten principles of holobionts and hologenomes. PLoS Biol. 13, e1002226.

Brodie, E. D., and Ridenhour, B. J. (2003). Reciprocal selection at the phenotypic interface of coevolution. Integr. Comp. Biol. 43, 408-418. doi: 10.1093/icb/43.3.408

Brodie, E. D., Ridenhour, B. J., and Brodie, E. D. (2002). The evolutionary response of predators to dangerous prey: hotspots and coldspots in the geographic mosaic of coevolution between garter snakes and newts. Evolution 56, 2067-2082. doi: 10.1111/j.0014-3820.2002.tb00132.x

Bruno, J. F., Stachowicz, J. J., and Bertness, M. D. (2003). Inclusion of facilitation into ecological theory. Trends Ecol. Evol. 18, 119-125. doi: 10.1016/S0169-5347(02)00045-9

Buerger, P., Alvarez-Roa, C., Coppin, C. W., Pearce, S. L., Chakravarti, L. J., Oakeshott, J. G., et al. (2020). Heat-evolved microalgal symbionts increase coral bleaching tolerance. Sci. Adv. 6, eaba2498. doi: 10.1126/sciadv.aba2498

Burns, J. A., Pittis, A. A., and Kim, E. (2018). Gene-based predictive models of trophic modes suggest Asgard archaea are not phagocytotic. Nat. Ecol. Evol. 2, 697-704. doi: 10.1038/s41559-018-0477-7

Cardini, U., Bartoli, M., Lücker, S., Mooshammer, M., Polzin, J., Lee, R. W., et al. (2019). Chemosymbiotic bivalves contribute to the nitrogen budget of seagrass ecosystems. ISME J. 13, 3131-3134. doi: 10.1038/s41396-019-0486-9

Carthey, A. J. R., Gillings, M. R., and Blumstein, D. T. (2018). The extended genotype: microbially mediated olfactory communication. Trends Ecol. Evol. 33, 885-894. doi: 10.1016/j.tree.2018.08.010

Cheng, D., Chen, S., Huang, Y., Pierce, N. E., Riegler, M., Yang, F., et al. (2019). Symbiotic microbiota may reflect host adaptation by resident to invasive ant species. PLoS Pathog. 15, e1007942. doi: 10.1371/journal.ppat.1007942

Claar, D. C., McDevitt-Irwin, J. M., Garren, M., Vega Thurber, R., Gates, R. D., and Baum, J. K. (2020). Increased diversity and concordant shifts in community structure of coral-associated Symbiodiniaceae and bacteria subjected to chronic human disturbance. Mol. Ecol. 29, 2477-2491. doi: 10.1111/mec.15494

Coats, V. C., and Rumpho, M. E. (2014). The rhizosphere microbiota of plant invaders: an overview of recent advances in the microbiomics of invasive plants. Front. Microbiol. 5, 368. doi: 10.3389/fmicb.2014.00368

Coleman, M. A., and Goold, H. D. (2019). Harnessing synthetic biology for kelp forest conservation1. J. Phycol. 55, 745-751. doi: 10.1111/jpy.12888

Collens, A., Kelley, E., and Katz, L. A. (2019). The concept of the hologenome, an epigenetic phenomenon, challenges aspects of the modern evolutionary synthesis. J. Exp. Zool. B Mol. Dev. Evol. 332, 349-355. doi: 10.1002/jez.b.22915

Correa, A. M. S., and Baker, A. C. (2011). Disaster taxa in microbially mediated metazoans: how endosymbionts and environmental catastrophes influence the adaptive capacity of reef corals. Glob. Chang. Biol. 17, 68-75. doi: 10.1111/j.1365-2486.2010.02242.x

Correa, A. M. S., Howard-Varona, C., Coy, S. R., Buchan, A., Sullivan, M. B., and Weitz, J. S. (2021). Revisiting the rules of life for viruses of microorganisms. Nat. Rev. Microbiol. 19, 501-513. doi: 10.1038/s41579-021-00530-x

Damjanovic, K., Blackall, L. L., Webster, N. S., and van Oppen, M. J. H. (2017). The contribution of microbial biotechnology to mitigating coral reef degradation. Microb. Biotechnol. 10, 1236-1243. doi: 10.1111/1751-7915.12769

Darwin, C. (1862). On the Various Contrivances by Which British and Foreign Orchids Are Fertilized by Insects. London: John Murray.

Davies, N. B. (2010). Cuckoos, Cowbirds and Other Cheats, 1st Edn. London: Bloomsbury Publishing.

Davy, S. K., Allemand, D., and Weis, V. M. (2012). Cell biology of Cnidarian-Dinoflagellate symbiosis. Microbiol. Mol. Biol. Rev. 76, 229-261. doi: 10.1128/MMBR.05014-11

De Bary, A. (1879). De la symbiose. Rev. Int. Sci. III, 301-309.
Degnan, S. M. (2014). Think laterally: horizontal gene transfer from symbiotic microbes may extend the phenotype of marine sessile hosts. Front. Microbiol. 5, 638. doi: 10.3389/fmicb.2014.00638

Dodd, M. E., Silvertown, J., and Chase, M. M. W. (1999). Phylogenetic analysis of trait evolution and species diversity variation among angiosperm families. Evolution 53, 732-744. doi: 10.1111/j.1558-5646.1999.tb05367.x

Doolittle, W. F., and Inkpen, S. A. (2018). Processes and patterns of interaction as units of selection: an introduction to ITSNTS thinking. Proc. Natl. Acad. Sci. U.S.A. 115, 4006-4014. doi: 10.1073/pnas.1722232115

Egan, S., and Gardiner, M. (2016). Microbial dysbiosis: rethinking disease in marine ecosystems. Front. Microbiol. 7, 991. doi: 10.3389/fmicb.2016.00991

Ehrlich, P. R., and Raven, P. H. (1964). Butterflies and plants: a study in coevolution. Evolution 18, 586-608. doi: 10.1111/j.1558-5646.1964.tb01674.x

Ezenwa, V. O., Gerardo, N. M., Inouye, D. W., Medina, M., and Xavier, J. B. (2012). Animal behavior and the microbiome. Science 338, 198-199. doi: $10.1126 /$ science. 1227412

Farrell, B. D. (1998). Inordinate fondness explained: why are there so many beetles? Science 281, 555-559. doi: 10.1126/science.281.5376.555

Field, J., Paxton, R. J., Soro, A., and Bridge, C. (2010). Cryptic plasticity underlies a major evolutionary transition. Curr. Biol. 20, 2028-2031. doi: 10.1016/j.cub.2010.10.020

Filbee-Dexter, K., and Smajdor, A. (2019). Ethics of assisted evolution in marine conservation. Front. Mar. Sci. 6, 20. doi: 10.3389/fmars.2019.00020

Fossøy, F., Sorenson, M. D., Liang, W., Ekrem, T., Moksnes, A., Møller, A. P., et al. (2016). Ancient origin and maternal inheritance of blue cuckoo eggs. Nat. Commun. 7, 10272. doi: 10.1038/ncomms 10272

Fox, J. W. (2005). Interpreting the "selection effect" of biodiversity on ecosystem function. Ecol. Lett. 8, 846-856. doi: 10.1111/j.1461-0248.2005.00795.x

Friedman, W. E. (2009). The meaning of Darwin's “abominable mystery." Am. J. Bot. 96, 5-21. doi: 10.3732/ajb.0800150

Gilbert, S. F., Bosch, T. C. G., and Ledón-Rettig, C. (2015). Eco-Evo-Devo: developmental symbiosis and developmental plasticity as evolutionary agents. Nat. Rev. Genet. 16, 611-622. doi: 10.1038/nrg3982

Gilbert, S. F., and Epel, D. (2015). Ecological Developmental Biology: The Environmental Regulation of Development, Health, and Evolution. Sunderland, MA: Sinauer Associates, Inc.

Gomaa, F., Kosakyan, A., Heger, T. J., Corsaro, D., Mitchell, E. A. D., and Lara, E. (2014). One alga to rule them all: unrelated mixotrophic testate Amoebae (Amoebozoa, Rhizaria and Stramenopiles) share the same symbiont (Trebouxiophyceae). Protist 165, 161-176. doi: 10.1016/j.protis.2014.01.002

Grant, V. (1949). Pollination systems as isolating mechanisms in angiosperms. Evolution 3, 82-97. doi: 10.1111/j.1558-5646.1949.tb00007.x

Grimaldi, D. (1999). The co-radiations of pollinating insects and angiosperms in the Cretaceous. Ann. Missouri Bot. Gard. 86, 373-406. doi: 10.2307/2666181

Grupstra, C. G. B., Rabbitt, K. M., Howe-Kerr, L. I., and Correa, A. M. S. (2021). Fish predation on corals promotes the dispersal of coral symbionts. Anim. Microbiome 3:25. doi: 10.1186/s42523-021-00086-4

Hallock, P. (1999). "Symbiont-bearing foraminifera," in B. K. S. Gupta, editor. Modern Foraminifera (New York, NY: Kluwer), 123-139. doi: 10.1007/0-306-48104-9_8

Hamilton, W. D. (2002). Narrow Roads of Gene Land: Evolution of Sex. New York: Oxford University Press.

Hansen, A. K., and Moran, N. A. (2011). Aphid genome expression reveals hostsymbiont cooperation in the production of amino acids. Proc. Natl. Acad. Sci. U.S.A. 108, 2849-2854. doi: 10.1073/pnas.1013465108

Hembry, D. H., Yoder, J. B., and Goodman, K. R. (2014). Coevolution and the diversification of life. Am. Nat. 184, 425-438. doi: 10.1086/6 77928

Herre, E. A., Knowlton, N., Mueller, U. G., and Rehner, S. A. (1999). The evolution of mutualisms: exploring the paths between conflict and cooperation. Trends Ecol. Evol. 14, 49-53. doi: 10.1016/S0169-5347(98)01529-8

Hillesland, K. L., and Stahl, D. A. (2010). Rapid evolution of stability and productivity at the origin of a microbial mutualism. Proc. Natl. Acad. Sci. U.S.A. 107, 2124-2129. doi: 10.1073/pnas.0908456107

Howe-Kerr, L. I., Bachelot, B., Wright, R. M., Kenkel, C. D., Bay, L. K., and Correa, A. M. S. (2020). Symbiont community diversity is more variable in corals that respond poorly to stress. Glob. Chang. Biol. 26, 2220-2234. doi: $10.1111 /$ gcb.14999

Hoyal Cuthill, J. F., and Charleston, M. (2015). Wing patterning genes and coevolution of Müllerian mimicry in Heliconius butterflies: support from 
phylogeography, cophylogeny, and divergence times. Evolution 69, 3082-3096. doi: 10.1111/evo.12812

Husnik, F., Nikoh, N., Koga, R., Ross, L., Duncan, R. P., Fujie, M., et al. (2013). Horizontal gene transfer from diverse bacteria to an insect genome enables a tripartite nested mealybug symbiosis. Cell. 153, 1567-1578. doi: 10.1016/j.cell.2013.05.040

Imachi, H., Nobu, M. K., Nakahara, N., Morono, Y., Ogawara, M., Takaki, Y., et al. (2020). Isolation of an archaeon at the prokaryote-eukaryote interface. Nature 577, 519-525. doi: 10.1038/s41586-019-1916-6

Ip, Y. K., and Chew, S. F. (2021). Light-dependent phenomena and related molecular mechanisms in giant clam-dinoflagellate associations: a review. Front. Mar. Sci. 8, 627722. doi: 10.3389/fmars.2021.627722

Janzen, D. H. (1980). When is it coevolution? Evolution 34, 611-612. doi: 10.1111/j.1558-5646.1980.tb04849.x

Kawaida, H., Ohba, K., Koutake, Y., Shimizu, H., Tachida, H., and Kobayakawa, Y. (2013). Symbiosis between hydra and chlorella: molecular phylogenetic analysis and experimental study provide insight into its origin and evolution. Mol. Phylogenet. Evol. 66, 906-914. doi: 10.1016/j.ympev.2012.11.018

Kay, K. M., and Sargent, R. D. (2009). The role of animal pollination in plant speciation: integrating ecology, geography, and genetics. Annu. Rev. Ecol. Evol. Syst. 40, 637-656. doi: 10.1146/annurev.ecolsys.110308.120310

Kiers, E. T., Palmer, T. M., Ives, A. R., Bruno, J. F., and Bronstein, J. L. (2010). Mutualisms in a changing world: an evolutionary perspective. Ecol. Lett. 13, 1459-1474. doi: 10.1111/j.1461-0248.2010.01538.x

Kiers, E. T., and Van Der Heijden, M. G. A. (2006). Mutualistic stability in the arbuscular mycorrhizal symbiosis: exploring hypotheses of evolutionary cooperation. Ecology 87, 1627-1636. doi: 10.1890/0012-9658(2006)87[1627:MSITAM]2.0.CO;2

Kiester, A., Lande, R., and Schemske, D. (1984). Models of coevolution and speciation in plants and their pollinators. Am. Nat. 124, 220-243. doi: $10.1086 / 284265$

King, K. C., Delph, L. F., Jokela, J., and Lively, C. M. (2009). The geographic mosaic of sex and the Red Queen. Curr. Biol. 19, 1438-1441. doi: 10.1016/j.cub.2009.06.062

Krüger, O., Sorenson, M. D., and Davies, N. B. (2009). Does coevolution promote species richness in parasitic cuckoos? Proc. R. Soc. B Biol. Sci. 276, 3871-3879. doi: $10.1098 /$ rspb.2009.1142

Lande, R. (2009). Adaptation to an extraordinary environment by evolution of phenotypic plasticity and genetic assimilation. J. Evol. Biol. 22, 1435-1446. doi: 10.1111/j.1420-9101.2009.01754.x

Leitão, A. L., Costa, M. C., Gabriel, A. F., and Enguita, F. J. (2020). Interspecies communication in holobionts by non-coding RNA exchange. Int. J. Mol. Sci. 21, 2333. doi: 10.3390/ijms21072333

Lesser, M. P., Stat, M., and Gates, R. D. (2013). The endosymbiotic dinoflagellates (Symbiodinium sp.) of corals are parasites and mutualists. Coral Reefs. 32, 603-611. doi: 10.1007/s00338-013-1051-z

Li, J., Lemer, S., Kirkendale, L., Bieler, R., Cavanaugh, C., and Giribet, G. (2020). Shedding light: a phylotranscriptomic perspective illuminates the origin of photosymbiosis in marine bivalves. BMC Evol. Biol. 20, 50. doi: 10.1186/s12862-020-01614-7

Lloyd, E. A., and Wade, M. J. (2019). Criteria for holobionts from community genetics. Biol. Theory 14, 151-170. doi: 10.1007/s13752-019-0 0322-w

Loreau, M. (1998). Biodiversity and ecosystem functioning: a mechanistic model. Proc. Natl. Acad. Sci. U.S.A. 95, 5632-5636. doi: 10.1073/pnas.95.10.5632

Mao, M., Yang, X., and Bennett, G. M. (2018). Evolution of host support for two ancient bacterial symbionts with differentially degraded genomes in a leafhopper host. Proc. Natl. Acad. Sci. U.S.A. 115, e11691-e11700. doi: $10.1073 /$ pnas. 1811932115

Margulis, L., and Fester, R. (1991). Symbiosis as a Source of Evolutionary Innovation: Speciation and Morphogenesis. Cambridge, MA: MIT Press.

Maron, J. L., Agrawal, A. A., and Schemske, D. W. (2019). Plant-herbivore coevolution and plant speciation. Ecology 100, e02704. doi: 10.1002/ecy.2704

Martin, W. F., Garg, S., and Zimorski, V. (2015). Endosymbiotic theories for eukaryote origin. Philos. Trans. R. Soc. B Biol. Sci. 370, 20140330. doi: 10.1098/rstb.2014.0330

Matthews, J. L., Raina, J. B., Kahlke, T., Seymour, J. R., van Oppen, M. J. H., and Suggett, D. J. (2020). Symbiodiniaceae-bacteria interactions: rethinking metabolite exchange in reef-building corals as multi-partner metabolic networks. Environ. Microbiol. 22, 1675-1687. doi: 10.1111/1462-2920.14918

McCutcheon, J. P., McDonald, B. R., and Moran, N. A. (2009). Convergent evolution of metabolic roles in bacterial co-symbionts of insects. Proc. Natl. Acad. Sci. U.S.A. 106, 15394-15399. doi: 10.1073/pnas.0906424106

McCutcheon, J. P., and Moran, N. A. (2012). Extreme genome reduction in symbiotic bacteria. Nat. Rev. Microbiol. 10, 13-26. doi: 10.1038/nrmicro2670

McIlroy, S. E., Cunning, R., Baker, A. C., and Coffroth, M. A. (2019). Competition and succession among coral endosymbionts. Ecol. Evol. 9, 12767-12778. doi: 10.1002/ece3.5749

McIlroy, S. E., Wong, J. C. Y., and Baker, D. M. (2020). Competitive traits of coral symbionts may alter the structure and function of the microbiome. ISME J. 14, 2424-2432. doi: 10.1038/s41396-020-0697-0

Melo Clavijo, J., Donath, A., Serôdio, J., and Christa, G. (2018). Polymorphic adaptations in metazoans to establish and maintain photosymbioses. Biol. Rev. 93, 2006-2020. doi: 10.1111/brv.12430

Mitter, C., Farrell, B., and Wiegmann, B. (1988). The phylogenetic study of adaptive zones: has phytophagy promoted insect diversification? Am. Nat. 132, 107-128. doi: $10.1086 / 284840$

Mizuuchi, R., and Ichihashi, N. (2018). Sustainable replication and coevolution of cooperative RNAs in an artificial cell-like system. Nat. Ecol. Evol. 2, 1654-1660. doi: 10.1038/s41559-018-0650-Z

Moran, N. A., and Sloan, D. B. (2015). The hologenome concept: helpful or hollow? PLoS Biol. 13, 1-10. doi: 10.1371/journal.pbio.1002311

Morella, N. M., Weng, F. C. H., Joubert, P. M., Jessica, C., Lindow, S., and Koskella, B. (2020). Successive passaging of a plant-associated microbiome reveals robust habitat and host genotype-dependent selection. Proc. Natl. Acad. Sci. U.S.A. 117, 1148-1159. doi: 10.1073/pnas.1908600116

Nakayama, T., Kamikawa, R., Tanifuji, G., Kashiyama, Y., Ohkouchi, N., Archibald, J. M., et al. (2014). Complete genome of a nonphotosynthetic cyanobacterium in a diatom reveals recent adaptations to an intracellular lifestyle. Proc. Natl. Acad. Sci. U.S.A. 111, 11407-11412. doi: 10.1073/pnas.1405222111

Nilsson, L. (1988). The evolution of flowers with deep corolla tubes. Nature 334, 147-149. doi: 10.1038/334147a0

Nuismer, S., Gomulkiewicz, R., and Ridenhour, B. (2010). When is correlation coevolution? Am. Nat. 175, 525-537. doi: 10.1086/651591

Nuismer, S. L., and Gandon, S. (2008). Moving beyond common-garden and transplant designs: insight into the causes of local adaptation in species interactions. Am. Nat. 171, 658-668. doi: 10.1086/587077

Oulhen, N., Schulz, B. J., and Carrier, T. J. (2016). English translation of Heinrich Anton de Bary's 1878 speech, 'Die Erscheinung der Symbiose' ('De la symbiose'). Symbiosis 69, 131-139. doi: 10.1007/s13199-016-0409-8

Page, R. D. M. (1996). Temporal congruence revisited: comparison of mitochondrial DNA sequence divergence in cospeciating pocket gophers and their chewing lice. Syst. Biol. 45, 151-167. doi: 10.1093/sysbio/45.2.151

Paterson, A. M., Wallis, G. P., Wallis, L. J., and Gray, R. D. (2000). Seabird and louse coevolution: complex histories revealed by $12 \mathrm{~S}$ rRNA sequences and reconciliation analyses. Syst. Biol. 49, 383-399. doi: 10.1080/10635159950127303

Peixoto, R. S., Harkins, D. M., and Nelson, K. E. (2021). Advances in microbiome research for animal health. Annu. Rev. Anim. Biosci. 9, 289-311. doi: 10.1146/annurev-animal-091020-075907

Pereira, H. M., Navarro, L. M., and Martins, I. S. (2012). Global biodiversity change: the bad, the good, and the unknown. Annu. Rev. Environ. Resour. 37, 25-50. doi: 10.1146/annurev-environ-042911-093511

Perez-Lamarque, B., Selosse, M. A., Öpik, M., and Morlon, H., Martos, F. (2020). Cheating in arbuscular mycorrhizal mutualism: a network and phylogenetic analysis of mycoheterotrophy. New Phytol. 226, 1822-1835. doi: $10.1111 / \mathrm{nph} .16474$

Pigluicci, M., and Muller, G. B. (2010). Evolution: The Extended Synthesis. Cambridge, MA: MIT Press. doi: 10.7551/mitpress/9780262513678.001.0001

Pita, L., Rix, L., Slaby, B. M., Franke, A., and Hentschel, U. (2018). The sponge holobiont in a changing ocean: from microbes to ecosystems. Microbiome 6, 46. doi: 10.1186/s40168-018-0428-1

Pogoda, C. S., Keepers, K. G., Lendemer, J. C., Kane, N. C., and Tripp, E. A. (2018). Reductions in complexity of mitochondrial genomes in lichen-forming fungi shed light on genome architecture of obligate symbioses. Mol. Ecol. 27, 1155-1169. doi: $10.1111 / \mathrm{mec} .14519$ 
Proeschold, T., Darienko, T., Silva, P. C., Reisser, W., and Krienitz, L. (2011). The systematics of Zoochlorella revisited employing an integrative approach. Environ. Microbiol. 13, 350-364. doi: 10.1111/j.1462-2920.2010.02333.x

Qiu, Z., Coleman, M. A., Provost, E., Campbell, A. H., Kelaher, B. P., Dalton, S. J., et al. (2019). Future climate change is predicted to affect the microbiome and condition of habitat-forming kelp. Proc. R. Soc. B Biol. Sci. 286, 20181887. doi: $10.1098 /$ rspb.2018.1887

Reshef, L., Koren, O., Loya, Y., Zilber-Rosenberg, I., and Rosenberg, E. (2006). The coral probiotic hypothesis. Environ. Microbiol. 8, 2068-2073. doi: 10.1111/j.1462-2920.2006.01148.x

Roughgarden, J., Gilbert, S. F., Rosenberg, E., Zilber-Rosenberg, I., and Lloyd, E. A. (2018). Holobionts as units of selection and a model of their population dynamics and evolution. Biol. Theory 13, 44-65. doi: 10.1007/s13752-017-0287-1

Russo, L., Miller, A. D., Tooker, J., Bjornstad, O. N., and Shea, K. (2018). Quantitative evolutionary patterns in bipartite networks: vicariance, phylogenetic tracking or diffuse co-evolution? Methods Ecol. Evol. 9, 761-772. doi: 10.1111/2041-210X.12914

Saha, M., Ferguson, R. M. W., Dove, S., Künzel, S., Meichssner, R., Neulinger, S. C., et al. (2020). Salinity and time can alter epibacterial communities of an invasive seaweed. Front. Microbiol. 10, 2870. doi: 10.3389/fmicb. 2019.02870

Sargent, R. D. (2004). Floral symmetry affects speciation rates in angiosperms. Proc. R. Soc. Lond. B. 271, 603-608. doi: 10.1098/rspb.2003.2644

Schlichting, C. D., and Pigliucci, M. (1998). Phenotypic Evolution: A Reaction Norm Perspective. Sunderland, MA: Sinauer.

Scotland, R. W. (2010). Deep homology: a view from systematics. Bioessays. 32, 438-349. doi: 10.1002/bies.200900175

Sloan, D. B., Nakabachi, A., Richards, S., Qu, J., Murali, S. C., Gibbs, R. A., et al. (2014). Parallel histories of horizontal gene transfer facilitated extreme reduction of endosymbiont genomes in sap-feeding insects. Mol. Biol. Evol. 31, 857-871. doi: 10.1093/molbev/msu004

Smith, C. I., Godsoe, W. K. W., Tank, S., Yoder, J. B., and Pellmyr, O. (2008). Distinguishing coevolution from covicariance in an obligate pollination mutualism: asynchronous divergence in Joshua tree and its pollinators. Evol. Int. J. Org. Evol. 62, 2676-2687. doi: 10.1111/j.1558-5646.2008. 00500.x

Smith, J. W., and Benkman, C. W. (2007). A coevolutionary arms race causes ecological speciation in crossbills. Am. Nat. 169, 455-465. doi: 10.1086/511961

Soler, J. J., Martínez, J. G., Soler, M., and Møller, A. P. (2001). Coevolutionary interactions in a host-parasite system. Ecol. Lett. 4, 470-476. doi: 10.1046/j.1461-0248.2001.00247.x

Soler, M., and Møller, A. P. (1990). Duration of sympatry and coevolution between the great spotted cuckoo and its magpie host. Nature 343, 748-750. doi: $10.1038 / 343748 \mathrm{a} 0$

Spottiswoode, C. N., and Stevens, M. (2012). Host-parasite arms races and rapid changes in bird egg appearance. Am. Nat. 179, 632-648. doi: 10.1086/665031

Stanley, G. D. (2006). Photosymbiosis and the evolution of modern coral reefs. 312, 857-858. doi: 10.1126/science. 1123701

Stiles, F. G. (1978). Ecological and evolutionary implications of bird pollination. Integr. Comp. Biol. 18, 715-727. doi: 10.1093/icb/18.4.715

Stoecker, D. K., Johnson, M. D., De Vargas, C., and Not, F. (2009). Acquired phototrophy in aquatic protists. Aquat. Microb. Ecol. 57, 279-310. doi: 10.3354/ame01340

Theis, K. R., Whittaker, D. J., and Rojas, C. A. (2020). “A hologenomic approach to animal behavior," in Evolution in Action: Past, Present and Future. Genetic and Evolutionary Computation, eds W. Banzhaf, B. Cheng, K. Deb, K. Holekamp, R. E. Lenski, C. Ofria, R. Pennock, B. Punch, and D. Whittaker (Cham: Springer), 247-263.

Thompson, J. N. (1989). Concepts of coevolution. Trends Ecol. Evol. 4, 179-183. doi: 10.1016/0169-5347(89)90125-0

Thompson, J. N. (1994). The Coevolutionary Process. Chicago, IL: University of Chicago Press. doi: 10.7208/chicago/9780226797670.001.0001

Thompson, J. N. (2006). Mutualistic webs of species. Science 312, 372-373. doi: 10.1126/science.1126904

Thompson, J. N., and Fernandez, C. C. (2006). Temporal dynamics of antagonism and mutualism in a geographically variable plant-insect interaction. Ecology 87, 103-112. doi: 10.1890/05-0123
Thurber, R. V., Payet, J. P., Thurber, A. R., and Correa, A. M. S. (2017). Virus-host interactions and their roles in coral reef health and disease. Nat. Rev. Microbiol. 15, 205-216. doi: 10.1038/nrmicro.2016.176

Tilman, D., Naeem, S., Knops, J., Reich, P., Siemann, E., Wedin, D., et al. (1997). Biodiversity and ecosystem properties. Science 278, 1865-1869. doi: $10.1126 /$ science. $278.5345 .1865 \mathrm{c}$

Trench, R. K. (1979). The cell biology of plant-animal symbiosis. Annu. Rev. Plant Physiol. 30, 485-531. doi: 10.1146/annurev.pp.30.060179.002413

van Oppen, M. J., and Medina, M. (2020). Coral evolutionary responses to microbial symbioses. Philos. Trans. R. Soc. B 375, 20190591. doi: 10.1098/rstb.2019.0591

van Oppen, M. J. H., Souter, P., Howells, E. J., Heyward, A., and Berkelmans, R. (2011). Novel genetic diversity through somatic mutations: fuel for adaptation of reef corals? Diversity 3, 405-423. doi: 10.3390/d3030405

Vernier, C. L., Chin, I. M., Adu-Oppong, B., Krupp, J. J., Levine, J., Dantas, G., et al. (2020). The gut microbiome defines social group membership in honey bee colonies. Sci. Adv. 6, eabd3431. doi: 10.1126/sciadv.abd3431

Waddington, C. H. (1953). Genetic assimilation of an acquired character. Evolution 7, 118-126. doi: 10.1111/j.1558-5646.1953.tb00070.x

Weiblen, G. D. (2004). Correlated evolution in fig pollination. Syst. Biol. 53, 128-139. doi: 10.1080/10635150490265012

West-Eberhard, M. J. (2003). Developmental Plasticity and Evolution. New York, NY: Oxford University Press. doi: 10.1093/oso/9780195122343.001.0001

Wittwer, B., Hefetz, A., Simon, T., Murphy, L. E. K., Elgar, M. A., Pierce, N. E., et al. (2017). Solitary bees reduce investment in communication compared with their social relatives. Proc. Natl. Acad. Sci. U.S.A. 114, 6569-6574. doi: 10.1073/pnas.1620780114

Wood, G., Marzinelli, E. M., Coleman, M. A., Campbell, A. H., Santini, N. S., Kajlich, L., et al. (2019). Restoring subtidal marine macrophytes in the Anthropocene: trajectories and future-proofing. Mar. Freshw. Res. 70, 936-951. doi: 10.1071/MF18226

Yang, C., Liang, W., Cai, Y., Shi, S., Takasu, F., Møller, A. P., et al. (2010). Coevolution in action: disruptive selection on egg colour in an avian brood parasite and its host. PLoS ONE 5, e10816. doi: 10.1371/journal.pone.0010816

Yoder, J. B., Nuismer, S. L. (2010). When does coevolution promote diversification? Am. Nat. 176, 802-817. doi: 10.1086/657048

Zaneveld, J. R., McMinds, R., and Thurber, R. V. (2017). Stress and stability : applying the Anna Karenina principle to animal microbiomes. Nat. Microbiol. 2, 17121. doi: 10.1038/nmicrobiol.2017.121

Zhu, F., Cusumano, A., Bloem, J., Weldegergis, B. T., Villela, A., Fatouros, N. E., et al. (2018). Symbiotic polydnavirus and venom reveal parasitoid to its hyperparasitoids. Proc. Natl. Acad. Sci. U.S.A. 115, 5205-5210. doi: $10.1073 /$ pnas. 1717904115

Zimmerman, A. E., Howard-Varona, C., Needham, D. M., John, S. G., Worden, A. Z., Sullivan, M. B., et al. (2020). Metabolic and biogeochemical consequences of viral infection in aquatic ecosystems. Nat. Rev. Microbiol. 18, 21-34. doi: 10.1038/s41579-019-0270-x

Conflict of Interest: The authors declare that the research was conducted in the absence of any commercial or financial relationships that could be construed as a potential conflict of interest.

Publisher's Note: All claims expressed in this article are solely those of the authors and do not necessarily represent those of their affiliated organizations, or those of the publisher, the editors and the reviewers. Any product that may be evaluated in this article, or claim that may be made by its manufacturer, is not guaranteed or endorsed by the publisher.

Copyright (c) 2022 Medina, Baker, Baltrus, Bennett, Cardini, Correa, Degnan, Christa, Kim, Li, Nash, Marzinelli, Nishiguchi, Prada, Roth, Saha, Smith, Theis and Zaneveld. This is an open-access article distributed under the terms of the Creative Commons Attribution License (CC BY). The use, distribution or reproduction in other forums is permitted, provided the original author(s) and the copyright owner(s) are credited and that the original publication in this journal is cited, in accordance with accepted academic practice. No use, distribution or reproduction is permitted which does not comply with these terms. 


\section{GLOSSARY}

One serious impediment to progress in coevolutionary research is the lack of consistency in the definition of the terms themselves. Since there are ongoing debates on concepts and terminology, we present a glossary with the definitions we are using throughout this manuscript. We call on future authors to state clear definitions that can be used to guide both the design and the interpretation of future research.

Antagonism: An association in which one organism typically benefits at the expense of its partner (e.g., parasitism).

Coevolution: Reciprocal evolutionary change between interacting lineages.

Commensalism: An association in which one partner benefits and other partners are not affected by the interaction. Although it is often difficult to prove empirically that some partners do not gain any net benefit or harm from the relationship.

Facilitation: Species interactions in which at least one species typically benefits from another.

Guild: A group of species that exploit the same resources.

Holobiont: A host and its associated microbiome.

Hologenome: Sum of interacting genomes of the host and its associated microbiome.
Homology: A trait in two organisms that shares common ancestry.

Homoplasy: A trait that has evolved through reversal, parallel or convergent evolution (not by shared common ancestry).

Host: An organism, often multicellular or larger in size in the case of unicellular organisms, that harbors one or more organisms in or on itself.

Interactome: A protein-protein interaction network.

Microbiome: Genetic material of all microbes residing in on or a host.

Mutualism: An association in which all partners typically or predominantly benefit from associating with one another.

Phenotypic plasticity: Adaptive capacity of a genotype to develop different phenotypes in response to environmental variation.

Phylogenetic congruence: Reciprocal corroboration of phylogenetic trees inferred from independent sources of data.

Phylosymbiosis: Degree of similarity between microbial communities resembles host phylogeny.

Symbiosis: Intimate association between two or more species. The nature of the predominant outcome of the interaction (positive, neutral, negative) is not a property of the term (i.e., symbiotic does not equate with mutualistic). 